\title{
The ERNO Television Exchange
}

\author{
A Window on the Train of Trust in the Balkans
}

\author{
Ullamaija Kivikuru
}

\begin{abstract}
It is not so much our judgements as it is our prejudices that constitute our being. This is a provocative formulation, but I am using it to restore to its rightful place a positive concept of prejudice that was driven out of our linguistic usage by the French and the English Enlightenment. It can be shown that the concept of prejudice did not originally have the meaning we have attached to it. Prejudices are not necessarily unjustified or erroneous, so that they inevitably distort the truth. In fact, the historicity of our existence entails that prejudices, in the literal sense of the word, constitute the initial directness of our whole ability to experience. Prejudices are biases of our openness to the world. (Gadamer, 1976:9.)
\end{abstract}

The Balkans are a region with mountains and graveyards, bombed buildings forming ghostly reminders of the bitter past in the midst of deserted countryside as well as in city centres overtly filled with "urban normality", crowds busily running up and down - and satellite dishes, sometimes even two per house or balcony. Here sophisticated media professionals suddenly drop crudely formulated stereotypes of "all Serbs/Croats/Bosniaks" - as thinking or behaving in a certain way - although the reasoning underlying their presentations is otherwise fairly elaborate. In everyday situations, it seems essential to "place" people ethnically - to know where a colleague's father comes from or where someone has his/her family roots.

In the Balkans today, the sound of an exploding bicycle tire makes relaxed customers in a streetside cafeteria jump in alarm. In the Balkans today societies as a whole as well as individual citizens are searching for a re-established openness based on prejudices, simultaneously historical, present, erroneous, justified and real. A decade-long succession of wars still resides in the minds of people who try to understand each other and themselves. These people seek, every day, a phenomenon that Gadamer calls "effective history".

This is a story of one attempt to bring to the Balkans the type of media material which is meant to assist in coping with the complex contradictions and prejudices which are faced by the people in Bosnia-Herzegovina, Croatia, Slovenia, Serbia, Montenegro, Kosovo, and Macedonia on a daily basis. In Slovenia the strongest ethnic tensions seem to be fading away already.

As such this story is simple, perhaps even mechanistic. It concerns a newsfilm exchange system which tries to increase "normality" among the countries of the former Yugoslavia. The aim of this paper is, on the one hand, to discuss the editorial policy of a new exchange system, operating under extremely sensitive political conditions and, on 
the other, to bring this discussion to the sphere of time/space/place. If the idea of a news and feature service is to spread understanding and regional consciousness, what kind of services should it offer - and what is possible, in the given political and journalistic conditions? Are the only options heavy politics or light human interest stories, especially when the exchange is run by a big international, routine-based system?

\section{ERNO - a Window for Spreading Understanding?}

ERNO is the youngest of the four "regional windows" which the EBU has established during the 1990s as a counter-attack to claims that the EBU main feed EVN pays too much attention to ministers and other dignitaries, climbing into and out of cars and, in general, favours the big and the powerful in Europe. The idea behind the regional windows is to soften the crash-news profile of EVN - but rather without extra costs. Thus it can be said that EBU established its regional windows to increase the proportion of "soft" news focusing on particular regions and countries.

The five rich Nordic countries pay the extra costs of their own Nordic window and get a daily service of 25 minutes, to a large extent economic news and noteworthy features. The eastern European window ERNE inherited the legacy of Intervision which went down with socialism in eastern Europe. All EBU members pay the costs of this regional window, sending material for 15 minutes daily to countries which used belong to the socialist block in eastern Europe. ERNE focuses quite much on the hard news with a regional aspect, allowing nation-level politicians from Poland, Hungary, and Slovakia not only to get their message across but also to get their pictures through as well. The Mediterranean window is older than ERNO, but this service still operates on a once-a-week basis and even then poorly. A regional identity has not yet propelled this television exchange into proper operation. The baby window is then ERNO, a regional window for South East Europe.

ERNO differs from the other regional windows because it has a mission. It is a newsfilm service meant to promote peace, democracy and reconciliation among 12 countries $^{1}$ in its capacity as a member of the Stability Pact of the Balkans. Thus it can be claimed that ERNO's objective is to assist or strengthen a citizen culture to be engendered in the Balkans. ERNO is running with Finnish and Danish assistance.

ERNO started a news and feature exchange in November of 2000. By the end of June 2001, it had transmitted altogether 398 items in its five-days-a-week, 15-minute service. On normal days, 3-4 items are transmitted via Geneva to all the participants plus a few extra receivers (Euronews, Austrian, Italian, and German television companies) at 16.2516.40 CET. The material discussed in this paper was collected during a review mission in June-July 2001, when I visited the ERNO headquarters in Sarajevo plus five of the EBU desks ${ }^{2}$.

Of the members of the network, the Banja Luka television (BATRS) was first established in 1992 and its objective was clear: to bring forward Serb interests in BosniaHerzegovina. All the other companies operated before the 1990s as parts of a national Yugoslavian set-up. They had their own channels focussing on their own territories, but they also exchanged whole programmes vigorously, especially with neighbour stations. Instead, news and current affairs coverage of other parts of the former Yugoslavia was thinner than in, say, entertainment or sports. With some hesitation, one could claim that the war-mongering, spreading of hatred and xenophobia toward other nations in the former Yugoslavia was rather based on stereotypes formed in the course of history and 
on the relative ignorance of each other's present-day situation, than on overwhelming information used for political purposes. No doubt television played a crucial role in the process leading to the political instability instability in the 1990s. Depending on the opinion of thr interviewees, the television stations considered the worst in mongering hatred and war varied in their choices. The ones mentioned most frequently are Serbian and Croatian television.

The idea behind ERNO is to bring the power of television, so much misused previously, now to instigate peace and stability by showing how people live and solve their problems in the other countries of the region. ERNO is meant to catch a glimpse of everyday life at the neighbour's, into the living rooms next door.

One of the EBU rules is that when a news item gets hot, it is transferred from a regional window to the main feed, such as EVN. When the months-long political tensions burst out into open conflict in Macedonia in June 2001, the EBU sent a team with a mobile satellite from Geneva to Skopje, and the Macedonian television started to cover the conflict for the home audience only. Similarly, a flash news, say, from the Middle East might interrupt the Nordic, ERNE, ERNO, or Mediterranean transmission. ${ }^{3}$

\section{The ERNO objective: Media Pluralism}

The ERNO Project relies on the Stability Pact agreed upon in Dayton, USA, and the Charter for Media Freedom formulated by the states participating in the Pact. Also the participants were selected according to the Stability Pact. This is quite a natural choice for a "back-up" philosophy, because in the Charter, the participant states bind themselves to strengthening of media pluralism and media institutions implementing pluralism; media networks are explicitly mentioned in the Charter.

The tone in the Charter follows the official communication philosophy of western democracies, though not too many of these are today able to give such a whole-hearted support for media pluralism in their respective countries. Free enterprise frequently contradicts genuine media freedom. Further, the role of the government remains quite obscure in the declaration, despite the phrase in the introduction: "free flow of information and ideas and open discussion, without the interference of public authorities". The operational role of the participating governments remains indefinite, assuming that all governments consider freedom of expression as their ally. Thus the Charter gives fairly free hands to governments to operate in the field of media, as long as they claim to do so under the umbrella of media pluralism. This applies especially strongly to radio and television institutions, if their public service status is not clear. Misuse of such liberties is not a theoretical fear only. Perhaps the best examples of misuse can be found in the Balkans themselves. The majority of the broadcasting companies there, aiming at a public service function, have had serious difficulties in their endeavour to develop a public company into a public service company with an arms-length distance from power-holders.

The ideology expressed in the Charter follows closely the Libertarian media philosophy, which believes that the better people are informed of their "opponent's" doings and culture, the better are the chances to avoid conflicts or to release tensions, if there is a conflict situation already. The division into "us" and "them" becomes less obvious and thus allows more operational space for mutual understanding. However, another theoretical position is also available: that in a deeply infected social contradiction, information does not help but perhaps even worsens the situation. According to such a philoso- 
phy, exposure to even balanced reporting from "the other side" perhaps only strengthens outdated and biased stereotypes and leads to interpretations which increase tension and hostilities. In short, one's trust in the ability of the media to reconcile with a post-war peace is far less secure in such a philosophy.

Knowing how bitter the controversies in the Balkans are, this latter option could well have been possible there. But the international community has, as if unaware of such an option, rather exaggerated than downplayed the power of the media. ERNO has a slightly different background, although its financing comes from Nordic sources and its basic ideology does not differ much from the not-so-well-reputed international community in the Balkans. ERNO was developed, as a professional exercise, regarding how to increase relevant inside-region television programme exchange in long discussions between local journalists and their Nordic colleagues.

On the practical level, the project aims at improving the exchange of television material in the countries belonging to the former Yugoslavia, including other countries belonging to the Stability Pact. The aim is simply to give the television companies in these countries a chance to exchange programmes on a daily basis and thus to enable their audiences to observe how governments operate and what people in the region do in their everyday life.

\section{The Exchange: The Strong Get Stronger}

The daily programme "menu" is prepared by a two-person coordination crew in Sarajevo. So far, nothing is produced especially for ERNO. The exchange is composed of news and feature items originating from the newsrooms of the network members. The local EBU desks operate as mediators, preparing "dope sheets" in English, to accompany the items. Thus ERNO is a repackaging agency, but there are plans to introduce a special ERNO feature service and later to establish a 12-member production pool as part of the exchange. The ERNO office also prepares and distributes the only weekly event calendar in the Balkans.

After a somewhat quiet Christmas-New Year period 2000-2001, which was celebrated at different times by different religious communities, the supply of ERNO exchange has grown steadily as Table 1 indicates.

There are no statistics of the use of ERNO by members - nor of the EVN main feed, for that matter. The EBU collects membership fees, but it does not charge anything extra for the use of its transmissions. This has led to the fact that the members download everything, but the actual usage remains unknown. According to the estimates by the coordination office and the local EBU desks, the use of ERNO is 60-65\%, considerably higher than the estimates of the EVN usage (estimated to be around 30\%). The television companies in the Balkans are heavy users of all EBU materials, because the majority cannot afford the services of Reuters or APTN. Still, scarce resources alone cannot explain the popularity of the ERNO items. Obviously there is a genuine need to increase material covering the neighbours also. During the review mission, more than a dozen interviews with EBU desk editors were carried out in five companies. In these interviews, all placed the Balkan neighbours in the first sphere of news interest, followed by "EU Europe" or "occidental Europe". It was clear that the Balkans were considered as being one entity, separate from Europe. 
Table 1. Outputs of the ERNO Exchange, November 2000-June 2001

\begin{tabular}{|c|c|c|c|c|c|c|c|c|}
\hline Company & November* & December & January & February & March & April & May & June \\
\hline YURTS & 1 & 6 & 3 & 8 & 20 & 18 & 7 & 19 \\
\hline MKRTV & 3 & 5 & 2 & 2 & 11 & 7 & 4 & 3 \\
\hline ZZRTK & 1 & 6 & 1 & 0 & 1 & 0 & 3 & 3 \\
\hline BARTV & 2 & 1 & 0 & 3 & 19 & 12 & 6 & 18 \\
\hline SIRTVS & 3 & 5 & 4 & 9 & 10 & 8 & 6 & 14 \\
\hline HRHRTV & 1 & 7 & 0 & 10 & 12 & 12 & 10 & 5 \\
\hline BGBNT & 0 & 1 & 1 & 1 & 14 & 6 & 7 & 3 \\
\hline ROTVR & 1 & 7 & 10 & 3 & 8 & 10 & 0 & 5 \\
\hline HUMTV & 1 & 4 & 0 & 0 & 1 & 1 & 0 & 1 \\
\hline YURTVC & 1 & 5 & 2 & 1 & 0 & 0 & 0 & 1 \\
\hline ALRTV & 0 & 0 & 0 & 0 & 0 & 0 & 0 & 0 \\
\hline BATRS & 2 & 4 & 0 & 0 & 1 & 0 & 0 & 1 \\
\hline OTHER** & 0 & 0 & 0 & 0 & 1 & 2 & 2 & 3 \\
\hline CANCEL ${ }^{* * *}$ & 2 & 3 & 1 & 5 & 13 & 2 & 0 & 3 \\
\hline TOTAL & 14 & 48 & 22 & 31 & 85 & 74 & 47 & 77 \\
\hline
\end{tabular}

* Only 3 days. The activity started on Nov. $29^{\text {th }}, 2000$.

** ERNO office occasionally invites contributions from other companies, if they appear relevant to SEE countries (e.g. the Italian RAI on Mediterranean environment problems).

*** Cancellations refer to items which have been completed too late and thus missed the transmission. Still, they show a willingness to participate.

The Project provided all member companies with the basic equipment and basic telecommunications links necessary for full participation in the ERNO exchange. All the companies operate with extremely limited technical resources, but these have been especially scarce in Serbia where the NATO bombings destroyed the television station; the company is temporarily situated in an old film production building, and the whole company operates with three editing units, in Banja Luka, in Montenegro and in Tirana. The succession of wars has also broken such links between the companies which existed before the conflicts. Temporary terrestrial arrangements have been made to replace the broken links between Banja Luka and Sarajevo, and between Belgrade and Montenegro. In the arrangement of equipment and links, EBU and UNESCO have also been active ${ }^{4}$. Of the participants, the relatively most well-off companies are found in Zagreb and Ljubjana. Montenegro was not able to upload any of its own items for a 6-week period due to technical problems, and Republika Srpska has similar problems when the winter snow arrives, because the temporary terrestrial link to Sarajevo does not tolerate heavy winter weather.

The Project has never even aimed at leveling any of the obvious resource imbalances; moreover in the politically delicate Balkans, such an attempt would hardly succeed without complications. For example, the establishment of the ERNO pool - 12 cameras, 12 editing units, 12 cameramen and 12 journalists - has been delayed due to the fact that acquiring the equipment could not be phased as the Nordic donors first suggested. Suspicions of favouritism emerged immediately. 
The resource imbalances are reflected in the outputs, though in a rather mediated way. The "strong" companies have participated more eagerly, but the news scenery has driven some companies (e.g. Serbia) to participate even with extremely scarce resources (Table 2). Of the "outside" countries, Romania seems to be the most motivated for the ERNO exchange, while Hungary does not seem to bother too much with this regional window.

Table 2. Items Sent by Various Television Companies to the ERNO Exchange, November 2000-June 2001

\begin{tabular}{ll}
\hline YURTS (Serbia) & 81 \\
BARTV (Bosnia-Herzegovina) & 61 \\
SIRTVS (Slovenia) & 59 \\
HBHBTV (Croatia) & 57 \\
ROTVR (Romania) & 44 \\
MKRTV (Macedonia) & 37 \\
BGBNT (Bulgaria) & 33 \\
ZZRTK (Kosovo) & 14 \\
YURTVC (Montenegro) & 10 \\
HUMTV (Hungary) & 8 \\
BATRS (Republika Srpska) & 8 \\
ALRTV (Albania) & 0 \\
\hline
\end{tabular}

Thus the suppliers can be put into four different categories. The group of activists seems to develop in the course of the exercise. In this top four list belong the television companies of Serbia, Bosnia-Herzegovina, Slovenia, and Croatia. All are, in principle, big companies and they also represent countries where the output of news is both even and large.

The following group comprises regular providers. They send items on a fairly regular basis, but less actively than the top four. In their supply, events taking place in their territory are also reflected. These companies include the Romanian, Macedonian, and Bulgarian television companies. Their technical and human (in Bulgaria and Macedonia perhaps also political) resources are perhaps a little more limited than those of the activist group. The limitations caused by scarce resources are reflected in the situation in Macedonia: as soon as the newest conflict started, the Macedonian television sent nothing after May 2001. Others discussed the Macedonian issue with concern, but Macedonia only transmitted material for its home audience.

The group of occasional providers sends material every now and then. In this group, there are in fact two types of companies. Two have or have had either technical problems to upload stories, or their human resources are limited (Republika Srpska, Montenegro, Kosovo) or the company simply is not very interested in the exchange (Hungary). The group comprises Kosovo, Republika Srpska, Hungary and Montenegro.

The fifth group could be called passivists, and it does not appear on the graph at all. The Albanian television has not sent a single story for the exchange so far. Albania is the only member, which remained totally passive throughout the seven-month period. An interesting issue, perhaps partly explaining the passivity of the Albanian company, refers 
to the language question. With the exception of Albanians in Albania and in Kosovo, all other members of the network understand each other, though the Slovenian and Macedonian languages might cause some problems for the rest. The core of the exchange is composed of the companies representing the same language family - could a joint language be seen as a factor increasing cultural closeness, despite political and ethnic differences? And, on the other hand, could exactly the same issue be at least a side-factor for the fact that Albania has been so passive in the exercise?

Naturally, the main reason for a company to offer items to ERNO depends on the news scenery: when there are floods in the region or foreign dignitaries on a visit, stories are made to appeal to the home audience and offered to ERNO as well. However, the domination of the activists seems to have strengthened in the course of the exchange, disregarding the topical news arena. The more routinised the exchange has become, the more the same company names frequent the lists. For the small companies, the threshold is higher. For example, the EBU desk at the Republika Srpska television pointed out several times in June that they had offered more items than the exchange had accepted.

\section{Learning the Rules of the Game: Content Comparison}

For the review mission, I made a crude content analysis of the ERNO materials of November-December 2000 and March 2001, the idea being to assess whether or not any changes in news criteria have taken place during the so-called Pilot Phase of the Project. The analysis was based on so-called dope sheets prepared by the local EBU desks and accompanying the visual material.

The analysis is crude in the sense that each story is placed only in one category. ${ }^{5}$ That obviously creates a bias, which especially muffles down the proportion of politics, because in the majority of cases, there is a political sidetrack or other theme in the story. For example, an item describing negotiations between 2-3 countries in the Balkans carries a political undertone. Still, the story is placed under "Balkans"; as a matter of fact, practically all stories about the Balkans had a political character, but in the items on the Balkans, there was something of more practical politics also: region-wide meetings, negotiations on borders and assets, etc. So in November-December, the total proportion of political items was 34\% and in March 31\%. It can be said that at least one-third of the items seems to deal entirely with politics. In addition, especially in March more than half of the stories dealing with the international community also had a political character. Because its proportion in March was as large as 38\%, the total of politically inclined stories approached one-half of the items.

Some of the dope sheets were so short that it would have been difficult to judge, if another category would have been more appropriate. In general as well, the idea was only to give a feeling for the content of the stories. In such a case, one coding category per item can be considered as being exact enough. The categories were established after a scrutiny of the items. Hence there is, e.g., no category for sports, because no sports were transmitted. But ERNO has no right to do that. Sports coverage belongs to the sports feed of the EVN.

The legacy of the 1990s becomes visible not only in the numerous reports of seminars and conferences organised by the international community but also in bilateral or multilateral meetings regarding borders, assets, airline arrangements and social security issues to be settled from a new perspective. An item that falls into the category of economic or domestic news might still indicate more general problems - and no doubt is interpreted 
so by other participants using the item. In a way, such news clearly reflects a democratic element in an organised society. In the same way, ERNO has, throughout its operation time, emphasised parliamentary activities and elections. Again, this could be interpreted as a sign of normality.

In general, practically all items described events and processes happening either on the state level (majority, all categories) or dealing with individual citizens (minority, appearing in domestic, culture and feature). Extremely rarely such items were transmitted which could be considered as describing the public sphere or the civil society. This is quite an interesting notion, because during the Tito era, the former Yugoslavia was based on a kind of self-management of local organisations. This phenomenon is not found, at least not in the materials sent for the exchange. Another characteristic detail in all the material is that some $80-85 \%$ of the actors in the stories were men. Women had their say only in stories on culture, domestic issues (social policy, accidents), and features. This is obviously a reflection of the inbuilt male domination in the culture, because eight out of ten of the selectors at the EBU desks were women and hardly deliberately worked against women in this respect.

\section{Table 3. ERNO Content Categories (\%), November-December 2000 and March 2001}

\begin{tabular}{lcc} 
Category & Nov.-Dec. 2000 & March 2001 \\
\hline International community & 8 & 38 \\
Balkans & 8 & 20 \\
National politics & 26 & 11 \\
Conflict & 2 & 3 \\
Economy & 13 & 5 \\
Domestic issues & 13 & 7 \\
Crime & 7 & 2 \\
Culture & 5 & 5 \\
Features & 18 & 9 \\
Total & 100 & 100 \\
\hline
\end{tabular}

The first conclusion of Table 3 seems to be that the international community is given far more space in March than in November-December, and that national politics seem to have lost popularity as have the features as well. However, concerning politics, I tend to claim the opposite - that the proportion of politically oriented items is higher in March than at the opening phase of the exchange.

The exchange started with quite a strong enthusiasm, although the quiet Christmas season 2000-2001 was at the doorstep. The total number of items (62) was quite high for the introductory phase.

The largest group of items (26\%) at the initial stage dealt with national politics: elections, government crises and ministers uttering statements, especially in Romania with the presidential election, Serbia with regional results of the recent elections and in Macedonia where political tensions were already brewing. The political news transmitted was quite formal, clear-cut procedures or changes without speculations.

November-December 2000 were strongly flavoured with Christmas celebrations - in towns, but also in villages with local customs and ingredients - and there were quite 
many other light stories transmitted and offered: mushroom harvests, fierce dogs, wolves, bird-trapping, but also the mad cow disease, or rather, fear of its spreading into the Balkans, was reported. City and village pictures, suitable for background of a news flash later were transmitted quite frequently. Most of the companies lack archive pictures from other countries in the Balkans, and they wish to get this kind of material more often: street in the summer, streets in the winter, churches, villages. ${ }^{6}$ All in all, roughly one-fifth $(18 \%)$ of the items fell into the category of features.

Two equally large item groups (13\% both) dealt with the economy and with domestic issues. As in politics, economic items covered fairly formal issues (Serbian Chamber of Commerce activities, introduction of new bank notes in Serbia), but also economic contradictions such as trade union conflicts and strikes in Croatia. This is one of the few cases which described the public sphere activities in the region. An equally lively category was that on domestic issues: domestic violence in Macedonia, establishment of village schools in Kosovo, ordinary people's fears in Kosovo villages, and the situation of mentally handicapped children in Belgrade. It could perhaps be said that these two categories came closest to how news is understood in the EBU main feed. There was more action than in the statement-oriented political items, and simultaneously the fear and anguish brought their "real-life" flavour to the contents.

Three categories reached equal size (7-8\%): items dealing with issues shared by several countries in the Balkans, the international community, and crime. While reporting on the Balkans and the international community, the ERNO items covered negotiations on the properties of the former Yugoslavia, the free trade agreement between Croatia and Bosnia-Herzegovina and discussions between airline companies (Air Srpska, Air Bosna and Air Yugoslav), border disputes, KFOR and SFOR peace forces, international meetings and seminars (the Council of Europe seminar in Macedonia, the USAID seminar on free media in Kosovo, etc.) - again clear-cut events on a fairly high level. The most common crime items dealt with the mafia and human trade. The international community was interpreted in the analysis quite broadly, as the countries (governments, ministers), governmental groups and organisations from countries that are not included in the Stability Pact. This category also showed that so many basic issues remain unsolved in the Balkans: borders, assets, pensions.

News on open conflicts was limited, and so were items on culture - without Christmas and the reopening of an archaeological museum in Split, Croatia, there would have been practically nothing on culture. Some Christmas items (a chorus performing in caves, Christmas plays) were placed in this category, because they described various cultural customs. An item on poisonous toys sold to parents in Hungary, for example, was placed in the category of economic material. Tones of conflict were found in many political pieces, but no dramatic "medium-size" conflict was found in the Balkans in NovemberDecember.

One could accept the notions given by some interviewees during the review mission in June 2001. At the initial phase, there seems to have been some haphazard selections on the one hand, and extreme cautions on the other hand, especially when dealing with politics. Furthermore, the proportions of various categories reflect the politically quiet Christmas and New-Year period, spread over quite a long interval, because different denominations spend the holidays at different times. Also the international community was rather quiet due to the holiday season. Hence, the content choice reflected, to a large extent, the fact that the news scenery was peaceful and quiet. Items stressing democracy and human rights entirely were perhaps not too many, but there was a clear aim to em- 
phasise "normality": to show that the societies and social institutions under scrutiny operated according to accepted rules, or were designing such rules, and people also did "normal" things, such as preparing for Christmas festivities, on the one hand, and were fearful of social injustice - especially in Kosovo - on the other.

In the top six in the list of companies providing material were the Romanian ROTVR, the Slovenian SIRTVS, the Croatian HBHBTV, the Kosovo ZZRTK, the Serbian YURTS and the Macedonian MKRTV. The list partly reflects the news scenery with more frequent events to report (Kosovo, Macedonia, Serbia), and partly the fact that certain companies were considerably better prepared for such a new activity (Slovenia, Croatia). Romania represents an interesting case. The political arena with elections was lively there, but Romania - as the only one of the "outside" members of the exchange - also clearly indicated willingness to participate. This willingness has sustained itself and is continuing.

The total number of items in March 2001 was somewhat higher than during the first month (85), and also concerning the focus; there were clear-cut differences compared with the beginning, especially in the role of the international community which this time was by far the most frequently covered theme among ERNO items. In general as well, the selection of items seemed to resemble a "normal" supply of items by a regional window. It was strongly politically oriented, but offered also some light material. Naturally it can be said that the time for reporting was more filled with news items in March than in December, and that there were also such natural disasters as floods in the region. Still, the news selection of March gives a more established impression. Also variation within categories was smaller than in December. On the other hand, it can perhaps be said that the selection as a whole was less genuinely Balkan-oriented, offering endless numbers of seminars, visits and meetings, often though with a title which referred to reconciliation, democratisation and other problem areas typical to the Balkans. In short, ERNO seemed to have learned the rules of the EBU game.

Items covering the international community (38\%) and its activities in the Balkans were by far the largest category. During the month of March, Belgrade seemed to be the most popular target for a variety of activities concerning new policies which the international community tried to establish. Of the three most popular capitals in the ERNO selection, Belgrade definitely had the most political profile, while Sarajevo seemed to be the centre for human-rights related activities - for example, Carla del Ponte paid a visit to Bosnia-Herzegovina - and the share of Zagreb was the strongest in issues related to trade and commerce. However, Zagreb also had its share of media freedom seminars. The international community seemed to focus quite clearly on these three cities in its activities, though toward the end of the month, the international community also expressed more and more concern about the growing tensions in Macedonia. In addition, some of the items carried results achieved in the seminars and during the visits of dignitaries, but many others were routine statements by an individual dignitary or protocol reports on who met whom.

The second largest category (20\%) covered items on the Balkans. Bosnia-Herzegovina and Croatia achieved an agreement on human rights. Other Balkan countries expressed their concern about Macedonia, while not too many reports were filed by the Macedonian television itself. President Vojislav Kostunica visited Republika Srpska, a former Romanian Prime Minister died and others reacted to this, and the head of the Bank of Slovenia reacted to a statement of the Serbian prime minister Zoran Djindjic who suggested the return of the dinar as an all-Balkan currency. Individuals who had paid for 
social security in the former Yugoslavia were granted the right to receive a pension in Slovenia.

Items dealing with national politics concerned predominantly Serbia and especially the former president, Slobodan Milocevic. The most popular politician in the ERNO exchange in March 2001 was still the Yugoslavian Foreign Minister Goran Svilanovic, giving statements about a variety of issues. Svilanovic represented a new generation of Belgrade politicians, perhaps more easily accepted by the neighbours than either Kostunica or Djindjic, especially because the two were known as being rivals. Furthermoe, Svilanovic also has television charisma; he appeared as a television personality. Seminars were organised on a national basis in several countries of the region. Several of these even planned action against illegal immigration. On the other hand, a corridor railway was planned to again link Salzburg and Sofia. The city of Bucharest reacted against stray dogs, and this brought Brigitte Bardot into the country - was this a domestic news issue or an international human interest feature remains to be discussed.

The category of features had reduced considerably since December (9\%), but the scale of themes showed more social relevance than during the first month of the exchange. The Slovenian television reported about audience feelings before and after a football match between Slovenia and Yugoslavia, and there were still several items on individuals who had been hiding from the war for years and were just now coming back. In this category, there was also a banal rarity, definitely lacking any political flavour: an old man from Banja Luka was said to have married 161 times and his "achievement" was going to enter the Guinness Book of Records.

Floods dominated the category of domestic items (7\%), because there were floods in almost all the countries concerned. There was a census organised in Bulgaria. Taxi drivers demonstrated in Bulgaria for the murder of a 3-year-old boy - a taxi driver's son and demanded the return of the death penalty in the country. A commemoration of the first international skiing competition (1895) was organised in Slovenia, and Hungary celebrated the 1848 revolution.

The economy and culture received equal attention (5\%). The economy centred mostly upon the Chambers of Commerce and corruption policies, while the items on culture covered such rarities as the Martenitsas festival in Bulgaria, but also items with a clear human rights perspective, stressing the rights of minorities: ERNO reported on Bay ram festivities in Zagreb, Croatia, in Novi Pazar, Serbia, and in Sarajevo, Bosnia.

The categories of conflicts $(3 \%)$ and crime $(2 \%)$ received very few items, although a big heroine smuggling ring was revealed in Bulgaria. The conflict news dealt entirely with Macedonia. These categories are special in that, on the one hand, only crimes with assumed interest for the other countries in the Balkans are offered to the exchange and, on the other hand, a clear reluctance to report on conflicts was, quite understandably, evident in the March 2001 ERNO "menu". Stories of conflicts are no longer news in the Balkans...

Among the television companies offering items, four formed a distinct top group: Serbian, Croatian, Bosnia-Herzegovina, and Bulgarian television companies, the two following ones were the Slovenian and Romanian television companies. Of these, Bulgaria perhaps could be said to represent a country which happened to have quite a vivid news scenery that month, ranging from floods and heroine smuggling to official visits. Its share of the supply for other months varied considerably. In contrast to this, Serbia, Croatia, Bosnia-Herzegovina and Slovenia seemed to dominate the supplier's side month after month. 
What constructs a train of trust, stories about Milosevic or of the old man from Banja Luka? Not much can be said about the quality of the items based on dope sheets alone, but without hesitation one can state that especially the categories of features, culture and domestic issues show that the companies participating had understood the idea of ERNO and were no doubt committed to the course. The quality of visualisation varied considerably, but what strikes one most is how fast the isolated producers and gatekeepers, invalidated by scarce resources and stringent time pressures, easily learned the rules of the game. Since the 1970s, it has been documented that there is a strong trend to conformity in all television newsrooms in Europe ${ }^{7}$. The EBU desk officers in the Balkans proposed and transmitted images which were somehow associated with the location whether these were streets, houses, birds or politicians. These formed the identification poles for the locus, the decisive reason why just that particular story was told. But there was also reference to the time as well: images of popular and/or good-looking members of the present elites (close shots), while members of the elites who had lost power (e.g. Milosevic and his family) were not at all allowed these close-up shots. Soundbites were given either to the present political elite or to such exotic individuals like the man who married 161 times.

It would be worth the elaboration to analyse the delicate visual connotations of place and time given between the lines in such standard event-oriented news items of which all EBU feeds are composed. They are simple, systematic and highly routinised, creating both for the producers and the users a feeling of normality and professionalism. This is how a "proper" news item should be told, giving an eyewitness impression for the audience. That lesson was learned in the Balkans in less than half a year.

One could, of course, discuss further the style of reporting, both textually and visually. However, the dope sheets are short and lack depth. When we focus on the content of ERNO materials, the problem-setting could perhaps be vulgarised to a naïve or at least trivial-sounding question concerning news criteria:

For the course of reconciliation and the right to be understood, should ERNO focus on Slobodan Milosevic and the endless number of items which he and his wife, daughter, supporters and opponents produce, or should ERNO rather prefer such items as the story of an 83-year old man from Banja Luka, Republika Srpska, who has been married 161 times but now lives alone, disappointed with all women?

The choice is not an either/option, but rather a question of priorities. What should be emphasised more, in order to allow the various ethnic groups the right to be understood by others - is it information or more culturally biased material that generates a quest for reconstructing social contacts? Further, would it not be good for the highly politicised communities in the Balkans to laugh and have fun also?

It is always somewhat dangerous to try to interpret the selection of news, because it does and it should reflect the situation in the society concerned. Still, a month is a time long enough to draw some conclusions carefully. The selection of ERNO items had definitely become more professional and consistent in the course of four months, and issues related to democracy and human rights - sometimes as a first theme, sometimes as a sidetrack - received considerably more space and attention in March 2001. Perhaps it is justified to claim that genuine Balkan issues seem to be fewer in March than in December 2001, while more general themes representing stability and order have gained more attention. Accordingly, one could argue that in the course of "normalising" the regional feed to meet the EBU standards, ERNO had missed something that could be termed ethnic genuineness. If this is the only choice available, the course of professional journal- 
ism could be questioned. Further, for a Nordic analyst, the selection appears to have a strong bias for politics, but as the interviewees stated, the societies in the Balkans are now highly political. Hence the bias was perhaps justified. However, the claim of political hubris was based on statements by media professionals or professional politicians. Was their judgement valid? Did they know what the audience really wanted? Did they want to know - many seemed to have quite fixed perceptions about their audiences, assessed as the ignorant masses.

Probably they were not completely off in their assessment. The Balkans today are definitely an over-politicised region, and what makes the situation even more problematic is that there are various types of politics exercised in parallel. In the region as a whole, there are politics of ethnicity and politics of party interests exercised side by side, frequently even by the very same politicians. Thus the identification poles offered in the news items - often through visualisation - were not very clear for the viewers, either. They required quite a sharp sense of demarcation from the receiver side, which was lacking

What the ERNO transmission tried to do during the time of this analysis was to emphasise the role of democratic institutions, and thus to weaken the significance of stereotypes based on ethnicity. Accordingly, a statement by a high-ranking European politician did not mean the same as a statement by a Bosnian or Serbian minister. The story of the European minister was a protocol news item, perhaps even an indication of the fact that outsiders again tried to master the scene in the Balkans, while the news about a statement from a local politician indicated that the democratic system was functioning. Further, a few contradictory statements also broke stereotypes by their sheer existence. They showed that Serbs/Croats/Bosniaks had differing opinions among themselves, they argued about social issues, not based on ethnic background or religion, but on a political ideology. Such politicians as Milosevic did not actually pose a greater problem, because he was already on his way out. It could even be claimed that continuous news transmission perhaps extended the topicality of Milosevic, thus preventing the public from seeing what was new in the Belgrade political arena. News transmission can be quite conservative and blind to nuances of this kind in such situations.

On the other hand, in societies with fixed stereotypes, also light and harmless items such as the one on the old man and his 161 wives perhaps only strengthened the stereotype of Serb hegemony among Croats and Bosniaks. In Slovenia with a more relaxed political atmosphere, exactly this problem seems to come to the fore The television company there was not as interested in transmitting political statements. As features, it favoured narratives on missing relatives, soldiers who had been hiding for years and suddenly returned to their home village, and so on. While extremely careful in the formulations concerning political issues, the dope sheets of such items comprised surprisingly crude stereotyping of Serbs and Croats. Obviously the political crisis - in the Slovenian case, quite short and mild compared with all the others - already belongs to the past, to be occasionally remembered in Slovenia, but not in the rest of the Balkans. Such features might turn into a problem in the long run, if the political processes have disjunctures in various countries in the region and the degree of political tolerance differs from place to place. 


\section{Living with Prejudices}

The kind of "hangover" processes which are ongoing in the Balkans are extremely complex in countries which have experienced ethnic conflicts during which "the other" has been labelled sub-human and posing a fundamental threat to "our" security. These processes are mixtures of history, rationality and irrationality - and use media as a huge, capricious megaphone system. Multinational societies have long traditions of territorially concentrated ethnic communities living side by side and in the course of history have incorporated into a larger state. In contrast, in poly-ethnic states the cultural diversity arises from the $19^{\text {th }}$ and $20^{\text {th }}$ century migration of both persons seeking a better life and refugees fleeing oppression. (Kymlicka, 1995.) Researchers of ethnic minorities tend to imply that the rights of the various ethnic groups in multinational societies are more easily arranged than those in poly-ethnic societies. Evidence from the Balkans seems to suggest the opposite.

The sharpness of social differentiation makes the situation in the Balkans different from the "civilized" and sophisticated prejudices which Ruben Konig talks about while analysing the picture of Germany and Germans in Dutch television (Konig, 2001:247267). However, the theoretical framework remains the same as in Konig's article. Prejudices are not considered "good" or "bad" as such, but as part of normal social processes in society. Berger and Luckmann (1991/1966:45) defined them long ago in the following way: "The reality of everyday life contains typificatory schemes in terms of which others are apprehended and "dealt with"'. Categorization and stereotypes are important human conceptual tools to handle the world we live in. In the Balkans, the world just happens to be crude, cruel, and filled with barely healed wounds.

Together with the ethnicity-based hangover come several other basic processes. In Bosnia-Herzegovina every second person is out of work, in the other states the unemployment figures are between 35 and 40 percent. Accordingly, it is impossible for the majority to buy a newspaper per day - that means $0.5 €$ to be invested in the media, accumulating to $15 €$ per month which means a sum equivalent to the electricity bill. People in Bosnia-Herzegovina and Croatia can tolerate the $2.5 €$ annual television licence fee, but they cannot afford the daily newspapers which are, after all, known to be biased. Hence one should in fact buy at least two papers per day to get a more comprehensive picture of the situation. Still, people have acquired satellite dishes. In BosniaHerzegovina, it is clearly a tribute to CNN which reported so favourably about the Bosniaks during the war. In the other states, the acquiring of dishes relates more to the low credibility of the domestic media. While the majority is highly critical toward the international community operating in their own countries, they still tend to rely, when local issues are at stake, on $\mathrm{CNN}$, the $\mathrm{BBC}$, or on the various German channels relayed to the Balkans. Thus the dishes represent mistrust of the domestic media and their interpretation of the world.

Parallel to this, another trend contrary to the trust in foreign media is found in the Balkans. Some call it even "recolonisation" - we at the donor end have learned to give it far more respectable names such as "responsibility of the international community". The West has moved into the Balkans and, while pouring money and projects into these societies, it also implies that people in the Balkans do not know how to live together; they would kill each other if the international community left. Especially in Bosnia-Herzegovina, where the international community of at least 20,000 has dwelt for almost 10 years now, it has raised mixed feelings among the local population - proud of its history 
and uniqueness. The resident intellectuals have commented that the international community has tried to make them look like barbarians.

Cees Hamelink (1997:37-38) talks about the utmost importance of spotting and exposing crimes against humanity as early as possible. He suggests a Media Alert System (IMAS) to monitor incitement to war and other signs of an imminent conflict. He puts the responsibility, to a large extent, on the shoulders of the academic community, which is thus far not especially known for its civil courage. Hamelink's point is valid, although his argumentation sounds "bigbrotherly", allowing or even demanding that the international community keeps an eye on troublemakers, when human rights are in danger. Hamelink's IMAS ideology would not be very popular in the Balkans today. There have been too many well-meaning and wealthy members of the international community around in the region, spreading money to any group that promises to distribute the rhetoric of democracy and freedom of expression. In practice, that means the establishment of new media. As a result, there is no space for consistent media policies, say, in Sarajevo which until recently had the questionable honour of abiding the presence of 200 radio and television companies for a population of 350,000. Several countries in the Balkans are now preparing (Bosnia-Herzegovina, Serbia) or have just completed (Slovenia) new media laws, aimed at balanced journalism and public service broadcasting, but many professionals assess that the international community has ruined or at least disturbed these attempts by showing too much interest in these internal issues. Simultaneously the international community has totally mixed up the advertising markets by favouring certain - predominantly "independent" - media and ignoring others.

Further, the international community, in the name of promoting peace and democracy, removed all media heads, who had been working during the crisis, disregarding what they actually did. No doubt, television - the strongest news medium in an region where newspapers are both expensive, poorly distributed and one-sided - had been used as a tool for spreading hatred and xenophobic stereotypes, but the international community has in many respects also been quite blue-eyed and one-sided, generously giving money to anybody who has learned the rhetoric of free expression, ignoring a deeper analysis of the situation.

A framework for the objective of ERNO could be defined roughly in line with Charles Husband's ideas (1998: 139), such that:

The Right to be Understood would place upon all a duty to seek comprehension of the other. The right to be understood qualifies the right to communicate by rejecting and condemning egocentric and ethnocentric routines of engaging with the communicative acts of others.

In a more recent text, Husband has developed the same idea into a suggestion for a multiethnic public sphere to be constituted in societies with several ethnic groups. He admits that for the time being, it remains a utopian project (Husband, 2000: 213). Its basic requirement is - which is also defined in the same way in the Balkans' Stability Pact - a legal-political framework in which the distinctive histories and current experiences of differing ethnic groups can be formally recognized by the state. Thus a public sphere does not emerge without a pat on the head by the state, as contradictory as it might sound, according to Slavko Splichal has said while discussing the role of civil society in strongly market-oriented societies. The same applies to societies recovering from a conflict:

The relationship between civil society and the state is dialectically contradictory, as it represents dialectical interaction between the opposing tendencies of 
integration (the state) and differentiation (civil society), /.../ in the information age this interaction is becoming "paradoxical": the state itself, in some senses the "worst enemy" of civil society, has become, in the capitalist, parliamentarian countries, one of its safeguards /.../. Although the state attempts to dominate civil society, it cannot avoid protecting some of the fundamental dimensions of civil society by providing the overall legal framework of social relations not directly regulated by the state. This paradox is the basis for any possible process of democratisation. (Splichal, 1994:73-74.)

But before any organised public sphere can be born, a quest for renewing social contracts must be found in society. Raymond Williams once wrote:

We want to speak as ourselves, and so elements of the past of the language, that we received from our parents, are always alive. At the same time, in an extending community, we want to speak with each other, reserving our actual differences but reducing those we find irrelevant. (Williams, 1965:252.)

As such, one should be careful with such "wonder concepts" as the public sphere or the civil society or the Third Sector, which seem to solve all social problems. For example, in Robert Putnam's view, civic society is marked by the existence of social networks of reciprocity and trust (e.g. Putnam, 1993: 173-174). The combination might bring about a civilized community, but the same combination can also be made so that the end result is a closed network that oppresses at least some of its members. Unlike Putnam, A.B. Seligman tries to understand the concept of trust within its historical framework. Seligman distinguishes between trust in individuals and trust in institutions and abstract systems. He reserves the concept of trust for the former and applies the concept of confidence to the latter. (Seligman, 1997:18.) Of course, the two concepts are intertwined and basically refer to the same thing: the future and its predictability. Still, especially when we talk about the situation in the Balkans, such a distinction is useful. In order to bring about a sound, trustworthy civic society, both trust in individuals and confidence in social institutions are needed. Perhaps the problem could be simplified as the concept of the"train of trust" (Coleman, 1988), which in the sociological discourse often refers to indirect personal contacts. The final aim is to create a train of trust among the people living in the Balkans, but the train also uses social institutions such as the media as its vehicles.

The mediascape in the Balkans is quite controversial. On the one hand, the masses have been led by television. Television gives the interpretation of the outside world, but simultaneously the book culture is important. In many situations the book appears as a more significant medium than the newspaper. And simultaneously, people with very limited language competence still acquire satellite dishes and follow the programming, assessing foreign stations as more credible. What this actually means is that they assess domestic media as lacking credibility. In short, one can hardly claim that the mediascape encourages to discussion and debate. It is an interesting, though partly contradictory, apparatus and it predominantly plays with images. News is appreciated, but it often reaches an individual via a two-step or multi-step flow. Books and music are important for the cultural identity, and the public dwelling with in the mediascape is deeply divided into two stereotypes: "modern", urban individuals and a rural mass composed of old and middle-aged citizens. The only medium that these groups share is television.

Television is a popular medium, in fact, the medium of choice for the masses in the Balkans. On the other hand, it is a medium that deals with estimates, rough images rather 
than exact information. The elaborations which Karin Becker, Jan Ekecrantz and Tom Olsson bring up while discussing the role of photographs in journalism (Becker et al., 2000: 8-9) is valid here as well. When television is used as a tool for reconciliation, the question relates to pictures of politics, the politics of pictures, as well as the politics of picturing politics from the producer's pespective. At the pilot phase, the focus is mainly on the two latter ones, the politics of pictures and the politics of picturing politics. The first question - in the Swedish text the most elementary one - no doubt receives here the least attention. It is the selection of themes and items the project deals with, rather than a focus on the quality or accuracy of the pictures.

The indigenous and exogenous interpretations of the news values might differ significantly, even concerning the agenda of the news. (e.g. McCombs \& Shaw, 1972). The agenda should be reflected against the whole social scenery. For the time being, the Balkans are highly politicised societies. Hence items with political value are worth transmission, because they are utilised. For example, there is a need to follow what is going to happen to Slobodan Milosevic. This does not necessarily mean that the receiver by any means agrees with Milosevic's policies - but still everyone feels necessary to update his/ her information about what happens to the icon of the problems of the 1990s.

Accordingly, it is important to point out that the ERNO exchange is meant to strengthen democratic thinking among the Balkans, not necessarily among Nordic researchers or the international community in the Balkans, who are filled with fixed ideas about democracy and human rights. The substance of these concepts has been brought from abroad. It is easy to talk about democracy in abstract, obscure terms, but what is needed here is the phenomenon which Peter Dahlgren terms as "civic culture" (1999). ERNO was established to strengthen civic culture in the Balkans, not in the international community. Here I give the same meaning to civic culture as Dahlgren (1999, 140-144), who views it as being composed of four dimensions:

- relevant knowledge, competence and engagement. People must have access to credible and multiple information, describing and giving meaning to formations constructing the world around them; they must have access to analysis, interpretation, reflection and debate on social activity. Here the contradictory mediascape in the Balkans should be taken into account;

- loyalty to democratic values and processes. Without such virtues as tolerance and the will to follow the democratic rules of the game, democracy does not operate. This aspect refers to Seligman's confidence. In the Balkans, this is one of the sore points of the society; people have very contradictory opinions about promotion of democracy, and the media have a role to play here.

- practice, routine, tradition. It is important that democracy does not remain as rhetoric only. It should embody itself in the everyday activities of the public sphere and in the lifeworlds of citizens. This dimension comprises activities with strong symbolic and historical components, such as election campaigns and daily routines such as meetings. Michael Billig calls such phenomena "banal nationalism" (Billig 1995). In the Balkans, the practical side of public life has often been stressed in attempts to promote democracy and the historical side muffled, because it is also the source for many uncontrolled prejudices.

- people's identity as citizens. This includes people's subjective perception of themselves as members in democratic communities. Perhaps Gellner's idea of a "modular man" (1994) is relevant here. Gellner claims that a man creates multiple identities 
without any of these "eating up" others. A citizen identity can be reflected as civic or political togetherness parallel on the international, national, or local level. A citizen identity does not follow formal political structures, though citizenship always includes juridical rights and responsibilities. Citizenship also has its cultural side (e.g. Mouffe 1993), and people can "be" citizens in a variety of modes and levels, the nation state representing just one among these. Here we deal predominantly with Seligman's trust.

In an ideal case, the ERNO exchange could raise the information level of the publics in the Balkans, to bind them to democratic practices and concrete day-to-day routines with a democratic flavour, and encourage them in their search for a citizenship in the postconflict situation, still extremely sensitive in political and ethnic terms. The demarcation of the political and the ethnic should perhaps be discussed more profoundly here, but that would lead us quite far from the problem-setting in this paper: if there is a system of distributing television news items in conflict-ridden societies, what kind of items should be exchanged in order to promote democracy?

Annabelle Sreberny concludes her considerations on various options available for television broadcasting of and for ethnic minorities in Great Britain in the following way:

All of this suggests that the representation of specifically minority ethnic themes, ideas and orientations is less and less likely to be encouraged, while a more diverse and diffuse multicultural orientation might be supported by the new organisational processes and commercial pressures. This can be seen optimistically as an opening of a window of opportunity, with a new wind of diversity to blow through it. But this needs monitoring to ensure that the same dynamics of exclusion and misrepresentation do not simply continue under new guises. (Sreberny, 1999:120.)

Sreberny's warning of ethnic absolutism is even more appropriate in the Balkans with somewhat hostile ethnic groups of roughly the same size. Tolerance does not mean that all oddities of a particular culture are brought under the microscope in television coverage. Rather the opposite, perhaps also oddities are understood when a "train of trust" based on common denominators is first developed.

Thus the significance of the indigenous and exogenous interpretations should once again be emphasised here; the prejudices of the Balkans and the international community are simultaneously intriguingly similar and different. From a gender perspective most stories on Slobodan Milosevic represent a type of political personality news coverage that we seem to be well acquainted with. He has been close to his strong wife Mirjana Markovic and their daughter - and exactly this is one of the qualities which make him difficult to be accepted in the strongly male-chauvinist culture in the Balkans. In contrast, the old man from Banja Luka, showing his open disgust for the whole female gender, sounds far more easily acceptable, though most people are amused by the fact that he has had time, energy and motivation to marry so many times. A fairly traditional image of women frequents the Balkan media, although about one-half of the journalists in the former Yugoslavia are women. The strong woman representation in the profession is at least partly due to the fact that journalism is a poorly paid occupation and totally lacks the glory attached to it in many other parts of the world. In the Balkans, journalists are still considered to be the errand boys and girls of politicians. From this perspective, a news feature on Milosevic shakes cultural values more than the human interest feature about the disillusioned old man in Banja Luka... 
There does exist a very real danger concerning news criteria, however, because there are already signs of it in the ERNO supply, when the "menus" of December 2000 and March 2001 were compared. ${ }^{8}$ This characteristic could be given a variety of names: for example, it could be called EBU pressure or a quest for quality journalism. In short, it concerns a desire to fit into mainstream journalism, there is a quest for conformity hidden in the hunger to formulate a solid policy line concerning the selection of items. The danger has not yet been great, because the majority of items relevant for the EVN have been fairly relevant for the Balkans as well, but the situation might change. Today, ERNO with its careful policy, and knowing that people are tired of conflicts, tends to muffle crisis news, but the EVN might consider the Balkans as a "trouble area" in years to come, thus stereotyping the region recovering from a crisis precisely with the image it wants to eliminate.

In the Balkans, the somewhat traumatic and contradictory relation to "occidental" Europe might become more complicated in the future. On the one hand, the societies in the Balkans consider themselves being outsiders in relation to Europe and being unnecessarily dominated and coached by Europeans in their own backyard; while on the other hand, Europe still provides a model for various social activities, in politics, and the economy, as well as in the mediascape.

\section{The Train of Trust and Ethnic Absolutism}

In the Balkans, the components of information, democratic institutions, and democratic routines are gradually strengthening themselves in the ideoscape, that is to say the ideological climate in the region. The media apparatus in any Balkan country that has come out of a deep crisis is gradually increasing the volume of relevant information about its own country and the neighbours; ERNO fits into this development very well. There is an unmistakable respect for democratic institutions and routines embedded in the ideoscape in the Balkans, although the form of these institutions and practices is somewhat diffuse in the minds of the people due to the socialist past. Many intellectuals - definitely not socialists by ideology - cherish the memory of the Tito era because the country was then unified and it fulfilled citizens' basic needs concerning education, health and social security. During the Tito era, uniformity was based on the greatest common denominator, while in the 1990s, the region has been split up because the smallest common denominators have served as the point of departure. It seems as though people had latched on to the ethnic issues because their trust in democracy departed with the weakening social institutions - this is how the power struggle at the top echelons has been reflected on the level of "ordinary people".

The degree of ethnic purity necessarily depends on its definition: what is considered genuine and pure is not always based on tradition and historical precedent, but on human will, on a deliberate decision-making process. Conformity in an ethnic group creates joint amnesia; a community "decides" to forget the issues its members disagree on. (Gellner, 1994.) Thus it can be claimed that the growth of ethnic absolutism in the Balkans is an unpremeditated impulse in answer to an increased insecurity in society on the part of the common people. These people stick to the few safety-nets which they are left with. Power-holders eagerly use absolute ethnicity and "authentic" traditions for their own purposes, and accordingly, a vicious circle is created. This has happened in Africa and India (e.g. Olaussen, 2001), and this seems to be the case in the Balkans also. 
Thus the task of all democracy-generating projects is to usher in a redefinition of ethnicity and thereby promote a cultural hybridity that challenges stereotypes and establishers precedence for co-existence with the existing prejudices in the sense which Gadamer uses the concept. Hybridity allows for an increase in openness, within which space for a proper public sphere could initially arise. Thus the aim is not to eliminate all prejudices, quite the opposite in fact: the idea in projects of reconciliation and democracy generation is to partly exploit, and partly challenge, the capacity built into existing prejudices. A human being without prejudices is, as Gadamer remins us, "mentally naked" and confused, whereby the idea of such efforts is to strengthen people's feelings of safety.

The beginning of ERNO has been surprisingly smooth. Obviously there has been a quest for such material and the material offered has been found relevant. Further, as long as the exchange concerns only the repackaging of already existing material, ERNO has perhaps been assessed as harmless. The situation might change, if the plans for a feature magazine programme and an ERNO pool of journalists will be implemented. In the delicate situation in the Balkans, especially the weaker partners (Montenegro, Kosovo, Macedonia) might raise the question of the stronger partners attempting to dominate the exchange. Signs of such a development can already be tracked down in Montenegro. A balancing factor, increasing considerably the credibility of the exchange, is that the head of the coordination is one of the most respected journalists in the region. He is Bosnian, but well-known in the whole region for his professionally high profile and independence during the war in Bosnia-Herzegovina.

However, obviously not even as modest a cooperation project as ERNO - even with the expertise of the coordinator available - could have been implemented without outside catalysts. This is one of the tragic features in the Balkans. People withdraw and criticize the international community, but simultaneously they depend on it, not only financially but also as a buffer zone. Still, one cannot avoid some frustration about the fact that in the Balkans, almost all imaginable faults and errors of development assistance in media and communication have been repeated in the Balkans. The international community has operated in a very arrogant manner, appearing as having learned nothing of their experiences in Africa, Asia, and Latin America.

The fact that ERNO has been a professional project, run by media experts (also at the Nordic end), has no doubt assisted in the acceptance of the project. Throughout the planning, pilot and project phases, the significance of public service broadcasting has been emphasised, and this fact might have greater importance in the partner companies, all aiming at a PSB function but still being quite far from it.

On the other hand, a service offering 3-4 items of which perhaps only a few seconds is used, cannot be an important tool for strengthening the right to be understood. Further, ERNO's political line has been extremely careful: it has transmitted descriptions of events and processes, no speculation or reflection, and the selection of persons allowed soundbites has been safe. These politicians have been men with esteem. If the exchange system develops its pool of journalists and cameramen, the situation might change, because such a pool easily selects controversial themes as well.

In summary, the beginning of ERNO seems to support an idea already well-known in development communication; that is, it is far easier to create new media institutions, if the basis already exists. Without the well-functioning bureaucracy and the massive satellites in Geneva, it would have been impossible to construct even the most modest version of a news exchange for the Balkans. The project exist insofar as the Geneva satellites are turned in a particular direction at a particular time to gather up a well-spring of 
images and to redistribute it. Further, the majority of the partner companies already knew how the EBU operates; the succession of wars in the Balkans had not swept away previous professional experience. ERNO has got a far better start than dozens of other media projects in the region, but ERNO also has had far more favourable circumstances as a project: basic infrastructures, a long tradition of media operations, and a professionalism that fits in well with the mainstream. But that also implies a tendency to incorporate the content into the mainstream. Perhaps something unique has been lost? Perhaps this is part of the paradoxical interaction between the opposing tendencies of integration (the state) and differentiation (the civic society) which Splichal talks about?

An indication of the level of ethnic absolutism, as a reflection of differentiating tendencies in the Balkans today, is the fact that all over the region, the differences in the Slav languages spoken by the half-a-dozen nations in the region are emphasised instead of stating bluntly that it actually concerns dialects of one single language. Particularity is brought to an extreme in the case of language, and the same applies to music, customs, and to political routines. Is it probable to unlock the difficult situation by bringing into such a culture the elements which stress the greatest common denominators (that is, the integrative tendencies), not only in political institutions but also in the culture as a whole? The train of trust is a local train, but its windows should be opened. But how can the mediascape assist in opening the windows? The best method appears as being a nonroutinised selection of material, surprises, confusing elements which offer a hammer to break down stereotypes and to reconstruct new ones. In short, a fairly courageous policy line, but implemented from inside the region. Only journalists from the Balkans know what kind of stereotypes to break apart and when the ideal time to do that would arrive. The role of outsiders - if any - should be just to provide the resources and to encourage a civic courage to follow through on it.

There is an extremely interesting paradox hidden in the modest selection of new items offered by the EBU regional feed for South East Europe: The idea behind all the regional windows is basically to soften the news selection, to use location as an interesting colourful speciality to give extra flavour to the main news feed. In the Balkans, the starting point is the "sense of borders" and its special values in the same way as in peripheral cultures which emphasise this particularity often to an extreme, in order to compensate for their isolation and feelings of inferiority. For the Balkans today, location - or more specifically, ethnicity within real boundaries - is often the starting point for activity. From this perspective, Sreberny's comment on the avoidance of 'pure' ethnic themes in television sounds relevant. Perhaps ERNO has a role to play in decreasing the power of this localization. Such a process could reduce location perhaps to something similar to an imaginary space, which is perceived as a supportive, perhaps a somewhat melancholic element in both an individual and his or her community's lifeworld (Moring, 2001). This applies especially to television because it plays with images and estimates.

From this perspective, it is perhaps less dangerous to update information on a Serb dictator, who has lost his power via democratic action, than to strengthen the male supremacy linked especially strongly with the Serbs (via elaborating on the juicy details of crazy human interest features such as the old man marrying and remarrying). This old man belongs to the realm of "banal nationalism" which Billig talks about, and the share of such banalities might be disproportionate in cultures which are not very tolerant. The old man from Banja Luka strengthens the stereotype of a Serb in the eyes of Bosniaks and Croats, perhaps even Serbs themselves. A good, relevant stop for the train of trust is the fact that ERNO emphasises the role of democratic institutions. They also form part 
of banal nationalism. In fact, the sheer existence of ERNO works on cultivating such a direction, because ERNO enables the region to exist in the news bulletins on a regular basis.

But in the final analysis, what is democracy? Is it a set of sophisticated principles, practices and traditions also present in societies which have recently experienced a succession of cruel trial-and-error crises? Or is it simply a method to survive, to ensure oneself and one's immediate surroundings a relatively safe future, perhaps partly with means that do not fit into the definitions of democracy and citizenship? The relevance of political action is always finally tested on the local level - perhaps the same applies to democracy and communication on the part of democracy? Perhaps democracy in the Balkans should be composed of slightly different ingredients than, say, in the Nordic countries? And what is the role of the media in such exercises, is the only option for the media to operate as a "window", as the EBU vocabulary indicates, or could one think that the media could be march at least a step ahead of the public? In this sense, advocates of media freedom believe in the flagship function of the media.

I do not know. The review task was simply too complex for my capacity to comprehend and draw clear-cut conclusions. The only thing I do know is that I strongly hesitate to justify the theoretically defined ideas such as Hamelink's IMAS system, at least when applied to the Balkans. As such, it is a detail in the set-up of the Balkans, but it could be viewed as a textbook example of over-simplification of a culturally (and politically) extremely delicate problem. It easily develops into an informer society, a we-know-better atmosphere which might lead to the tendencies of recolonisation. Could the international community, speaking in the name of democracy and human rights, be given the right to judge the internal affairs of a particular country, without working with, and through, the locals? Hamelink connects his discourse with monitoring the local media. The monitoring aspect is valid and essential, but rather than to operate as an international fire alarm, local-media monitoring could be used to sensitize local-media professionals to imbalances, biases and stereotypes and thus encourage debate and discussion inside the society. It is not an easy task, because media professionals in the Balkans lack resources, esteem and self-confidence. All this makes them into a fairly conservative group, resistant to change. But they are also extremely tired of 'know-it-alls' from "occidental” Europe, despite their thick wallets.

\section{Notes}

1. The members of the ERNO exchange are public or public service broadcasting companies in ALRTV in Tirana, Albania, BARTV in Sarajevo, Bosnia-Herzegovina, BATRS in Banja Luka Republika Srpska, BGBNT in Sofia, Bulgaria, HRHRTV in Zagreb, Croatia, HUMTV in Budapest, Hungary, MKRTV in Skopje, Macedonia, ROTVR in Bucharest, Romania, SIRTVS in Ljubjana, Slovenia, YURTS in Belgrade, Serbia, YURTVC in Podgorica, Montenegro and ZZRTK in Pristina, Kosovo. However, the Albanian television has never participated in uploadings, but it has downloaded some ERNO materials how much is difficult to know. Of the Stability Pact countries, the broadcasting companies of Greece and Turkey are missing. At the time of the establishment of the exchange they did not show interest to join, but negotiations are going to restart soon. Of the members, all other than the Serbian and the Montenegro televisions are EBU members. The remnants of the former Yugoslavia (in practice, just Serbia, Kosovo and Montenegro) were kicked out of the EBU during Slobodan Milosevic's regime. Negotiations for rejoining were completed in summer of 2001. In the meantime, the Finnish broadcasting company YLE paid for the extra telecommunication costs to enable Serbia, Kosovo and Montenegro to participate on equal terms.

2. Sarajevo, Banja Luka, Zagreb, Belgrade and Podgorica. 
3. All regional windows have experienced this, but especially for ERNE and ERNO, such interruptions are bitter and, according to local interpretations, indicate that their services are not valued properly in Geneva. In the Balkans, several EBU desk officers told a story of the most recent interruption, when a flash from the Gaza strip interrupted the transmission of a feature on Brigitte Bardot's visit to Bucharest to save local stray dogs, which the Mayor of Bucharest wanted to kill.

4. In general, the Finnish assistance covers all the operational costs (roughly two-thirds of the total) and the Danish assistance (Baltic Media Centre) all training and meetings (one-third). The Finnish implementing agency YLE gives all consultation free of charge, and the EBU assistance means that the EVN does not charge any extra costs, even for unilateral exchanges which ordinarily cost 400 Swiss franc per minute from Geneva to the Balkans. The monthly running costs (paid by Finns) of the coordination office are 15,000 FIM (2,500€). Until June 2001, all the expenses of the Project reached just 2 million FIM (336,000€). Thus ERNO is financially quite a modest exercise.

5. The categories were established after the first scrutiny of the material. They were the following:

1. International community (covering all activities, predominantly political, of the "outside world", operating both in the Balkans and outside)

2. Balkan (processes and events, predominantly political, inside the Balkans, touching more than one country)

3. National politics (domestic politics and the operation of political institutions)

4. Conflict (open conflict, military action)

5. Economy (private and public, state level, trade unions, individual entrepreneurs, etc.)

6. Domestic affairs (events, accidents, but also social life)

7. Crime

8. Culture (culture, education, arts)

9. Feature (human interest, less topical)

6. One of the most recent problems of this kind has been with Macedonia. During the review mission, several interviewees told about their futile attempts to get street pictures from Skopje and Tetovo to be used as background for news, but the Macedonian ERNO member totally dropped out when the crisis worsened.

7. See e.g. Varis \& Jokelin (1976) who argue that the Eurovision exchange is biased in the sense that more than $40 \%$ of the material deal with politics. However, the most significant issue that the researchers point out is the similarity of the then two ideologically quite different television exchange systems, Eurovision and Intervision.

8. An other indication of the same phenomenon is that several EBU desk editors seemed to be very proud of the fact that a few times the EVN main feed plus Euronews had adopted some of their items. They had selected "right" items for the exchange, because they were accepted by bigger international media.

\section{References}

Becker, K., Ekecrantz, J. \& Olsson, T. (2000) "Introduction: Picturing Politics in $20^{\text {th }}$ Century Sweden". In Becker et al. (eds): Picturing Politics. Visual and Textual Formations of Modernity in the Swedish Press. Stockholm: JMK (Skriftserie 2000:1).

Berger, P.L.\& Luckmann, T. (1991/1966) The Social Construction of Reality: A Treatise in the Sociology of Knowledge. Harmondsworth, UK: Penguin.

Billig, M. (1995) Banal Nationalism. London: Sage.

Coleman, J. (1988) "Social Capital in the Creation of Human Capital”. American Journal of Sociology 94.

Dahlgren, P. (1999) "EU, medborgarkultur och mediernas demokratiska uppgift" [The EU, civic culture and the democratic function of the media]. In Politikens medialisering, forskarvolym III. Statens offentliga utredningar SOU 1999: 126. Stockholm.

Findahl, O. (2001) "News in Our Minds". In Renckstorf, K., McQuail, D. \& Jankowski, N. (eds.): Television News Research: Recent European Approaches and Findings. Berlin et al.: Quintessence Publishing Co, Inc.

Gadamer, H.-G. (1976) Philosophical Hermeneutics. Berkeley: University of California Press.

Gellner, E. (1994) Conditions of Liberty. London: Allen Lane/Penguin.

Hamelink, C. (1997)"Media, Ethnic Conflict and Culpability". In Servaes, J. \& Lie, R. (eds.) Media \& Politics in Transition. Cultural Identity in the Age of Globalization. Leuven: Acco.

Husband, C. (1998) "Differentiated Citizenship and the Multi-Ethnic Public Sphere". Journal of International Communication 5. 
Husband, C. (2000) "Media and the Public Sphere in Multi-Ethnic Societies". In Cottle, S. (ed.): Ethnic Minorities and the Media. Buchingham/Philadelphia: Open University Press.

Konig, R. (2001) "On the Influence of Prejudice on the Production and Reception of Television News. Introducing Research on the Case of Germany and Germans in Dutch Television News". In Renckstorf, K. et al. (eds.): Television News Research: Recent European Approaches and Findings. Berlin et al.: Quintessence Publishing Co, Inc.

Kymlicka, W. (1995) Multicultural Citizenship. Oxford: Oxford University Press.

McCombs, M. \& Shaw, D.L. (1972) "The Agenda-Setting Function of the Mass Media". Public Opinion Quarterly, 36.

Moring, I. (2001) "Space and Politics of Identity. Imaginary Landscapes and Ideological Reproduction of 'We'". In Kivikuru, U. (ed.): Contesting the Frontiers: Media and Dimensions of Identity. Göteborg: Nordicom.

Mouffe, C. (1993) The Return of the Political. London: Verso.

Olaussen, M. (2001)"Varför somliga är mera etniska än andra" [Why some are more ethnic than others] Under sträcket. Hufvudstadsbladet July 30th,2001.

Putnam, R. (1993) Making Democracy Work. Civic Traditions in Modern Italy. New Jersey: Princeton University Press.

Seligman, A.B. (1997) The Problem of Trust. Princeton: Princeton University Press.

Splichal, S. (1994) "From Civil Society to Information Society?". In Splichal, S. et al.(eds.): Information Society and Civil Society. Contemporary Perceptions on the Changing World Order. West Lafayette, Indiana: Purdue University Press.

Sreberny, A. (1999) Include Me In. Rethinking Ethnicity on Television: Audience and Production Perspectives. London: Broadcasting Standards Commission in conjunction with the Independent Television Commission.

Varis, T. \& Jokelin, R. (1976) Television News in Europe. A Survey of the News-film Flow in Europe. Institute of Journalism and Mass Communication, University of Tampere 32.

Williams, R. (1965) The Long Revolution. Hammondsworth: Penguin.

\section{Interviews}

Blomberg, Jouko Project Coordinator,YLE 6.7, 13.7.2001

Ceremidzic, Milka, Managing Editor, PCPS (Republika Srpska, Banja Luka) 28.6.2001

Crkvenjakov, Alexander, Director General for RTS (Serbia, Belgrade) 30.6.2001

Dukanovic, Olivera, EBU, Montenegro television (Montenegro, Podgorica) 2.7.2001

Ilic, Nebojsa EBU desk, RTS (Serbia, Belgrade) 30.6.2001

Ivanovic, Marijana, Head of EBU desk, RTS (Serbia, Belgrade) 30.6.2001

Jovovic, Tiodora, EBU, Montenegro Television (Montenegro, Podgorca) 2.7.2001

Järvinen, Ari, News Editor, YLE 10.7.2001

Kamenica, Senad, ERNO Coordinator (Sarajevo) 26.6.,27.6., 4.7.2001

Kostovic, Katarina, EBU coordinator, HRT (Croatia, Zagreb) 9.6.2001

Kovacevic, Predrag, RTS, EBU \& regional desk (Serbia, Belgrade) 30.6.2001

Lepic, Zeljka, ERNO Assistant Coordinator (Sarajevo) 25.6.-4.7.2001

Omersoftio, Amilia, former Director General of BHT (Bosnia-Herzegovina, Sarajevo) 26.6.2001

Rajisic, Sandra, EBU coordinator, HRT (Croatia, Zagreb) 29.6.2001

Rajicic, Sasha, journalist \& EBU desk officer, PCPS (Republika Srpska, Banja Luka) 28.6.2001

Ramljak, Marija, EBU coordinator, HRT (Croatia, Zagreb) 29.6.2001

Skorin, Maksim, Editor of the Eurovision desk, HRT (Croatia, Zagreb) 29.6.2001

Topic-Crnoja, Marija, Head of News and Current Affairs, BHT (Bosnia-Herzegovina, Sarajevo) 26.6.2001

\section{Materials}

Dope sheets of ERNO exchange, November 29 ${ }^{\text {th }}, 2000$ - June $30^{\text {th }}, 2001$

SEE TV News Exchange. Pilot Phase Implementation Plan, dated 10.11.2000

SEE Television News Exchange ERNO: Programme Completion Report, dated 10.04.2001

ERNO South East European News Exchange for Public Service TV Broadcasters, dated 14.05.2001. 